\title{
12. Life on basic income - Interview accounts by basic income experiment participants on the effects of the experiment
}

\author{
Helena Blomberg, Christian Kroll and Laura \\ Tarkiainen
}

\section{INTRODUCTION}

The aims of the Finnish basic income experiment were strongly associated with the target population's employment status effects, since the main goals were to strengthen employment incentives and remove the conditionality of unemployment benefits. However, basic income proponents argue that the effects of basic income should be scrutinised in a broader sense than a narrow labour supply framework. For example, Van Parijs (2013) and Davala et al. (2015) claim that basic income is an emancipatory and participatory income promoting individuals' real freedom. In addition, as argued by Calnitsky (2016: 28), labour supply results tell little about how recipients experience basic income, and understand and interpret its effects. Thus, research on basic income experiments would benefit from considering various aspects of social and psychological consequences, as well as personal accounts by experiment participants on their effects.

In this chapter, we examine the effects of the Finnish basic income experiment by analysing qualitative interview accounts of 81 people who participated in the two-year experiment. In our theory-driven content analysis, we utilise Hannah Arendt's theory (Arendt, 1998 [1958]) on labour, work, and action modalities and Inger Jansson's interpretation of basic income's effects on these modalities (Jansson, 2019). By analysing interviewees' accounts in the light of Arendt's labour, work and action modalities, we aim to achieve a deeper understanding of the various effects of the basic income experiment.

We start by briefly introducing previous research on basic income and discussing our theoretical underpinnings. Then, we present our data and analysis 
process. Next, we examine the interviewees' accounts of the effects of utilising the framework of the labour, work and action modalities. In the concluding section, we reflect on our findings more broadly.

\section{ON THE EFFECTS OF A BASIC INCOME}

As pointed out elsewhere in this book, the concept of basic income has been discussed from a variety of theoretical and practical vantage points. For example, in Finland, basic income has been given multiple conflicting definitions, because it has been posited as a response to various issues, such as problems of welfare bureaucracy, fulfilment of social rights, incentives for paid work, and insecurity of 'precarious' employment (Perkiö, 2020a, 2020b). Thus, although basic income has often been presented as a simple and unified idea, concrete policy proposals have included varying goals and interpretations of it (De Wispelaere and Stirton, 2004). In the Finnish basic income experiment, the final design parameters can be regarded as the result of not only political, but also legal, institutional, and budgetary considerations and constraints (see De Wispelaere et al., 2018: 16).

Generally, existing research on basic income has largely focused on the normative discussions of its application, particularly with regard to work and employment (for reviews, see Kangas and Pulkka, 2016; Widerqvist, 2013). On the one hand, basic income is thought to incentivise paid work and provide a safety net and bargaining power to those who are subjected to insecure, poorly protected, and low-paid working conditions. Basic income is, for example, assumed to support those who perform sporadic and irregular entrepreneurial activities as well as project-based creative work (Jansson, 2019; Kangas and Pulkka, 2016). On the other hand, it is argued that basic income may present a risk of trapping precarious workers in insecure employment conditions (see Birnbaum and De Wispelaere, 2020).

Furthermore, it is claimed that basic income obscures the division between 'work' and 'non-work' (Pateman, 2004), when taking into account not just paid work in the labour market, but also the range of non-commodified forms of activities, such as domestic work, care work, community engagement, and voluntary work. In addition, basic income is thought to make it easier for an individual citizen to reduce working time, to take a break between jobs, to have the means to undertake further training, or to become self-employed (Van Parijs, 2001). Thus, it is argued that basic income challenges the centrality of paid work and decreases the shame and deleterious effects of unemployment (Sage, 2019). By various means, basic income may enhance individuals' freedom, autonomy, and emancipation (e.g. Standing, 2017; Van Parijs, 1995, 2013). 
Because of its universality principle, basic income has been considered to eliminate explicit or implicit moral judgements and to reduce benefit stigma (Calnitsky, 2016; McKay, 2007). It has been perceived as providing a humane alternative to conditional traditional means-tested workfare programmes (Hamilton and Mulvale, 2019).

While empirical evidence on various issues regarding the effects of basic income often seem inconclusive to date, existing studies have often followed a quantitative methodological approach. In the relatively scarce body of qualitative work on basic income experiments, some studies have reported reduced stigma under an unconditional regime with a mixed group of recipients (Calnitsky, 2016), while others have reported that basic income has positive effects on recipients' self-dignity and experiences of trust (Bohmeyer and Cornelsen, 2019). In addition, basic income has outperformed traditional conditional welfare programmes with respect to long-term financial and future planning, improved nutrition, housing stability, physical and mental health, and social connections with friends and family (see Hamilton and Mulvale, 2019).

\section{BASIC INCOME IN THE LABOUR, WORK AND ACTION MODALITY FRAMES}

As pointed out above, a basic income can be assumed to affect people's employment and life trajectories in various ways, although it is far from clear how, since the assumptions presented include conflicting and contradictory ideas and conclusions. By approaching the Finnish basic income experiment from the perspective of participating individuals, we aim here to account for people's various social contexts in which 'everything affects everything'. Hence, our point of departure is that basic income should be assessed in relation to individuals' larger life situations and social contexts. We assume that people as actors pay attention to various aspects of life when making decisions related to paid employment and activities outside the labour market.

Arendt's (1998 [1958]) theory, known as vita activa, provides a theoretical framework that takes into account these various aspects. The main principle of the theory is that human activity is conditioned under three modalities: labour, work and action. These three modalities include everyday survival and consumption, utility and production; creating permanence and coexistence among humans; and human flourishing.

Arendt's thought has increasingly inspired researchers interested in welfare policy and occupational science, including some interested in basic income (Jansson, 2017, 2019; Sauer, 2015; Suuronen, 2018). For example, Jansson (2019) analysed Arendt's theory vis-à-vis people's occupational patterns and their experiences of occupational meaning. According to this view, the 
rationale underlying claims for basic income relies on different ideologies that can all be examined through the lens of labour, work and action modalities. Therefore, the effects of basic income should be assessed through not just one but all modalities, since people participate more or less in all of them. First, the 'labour' modality refers to the abolishment of bureaucratic payment transfer systems and work that secures everyday survival through paid work. Within the labour modality, basic income may help to liberate people from impossible demands of the labour market, but may also result in the risk of them becoming passive consumers, unable to fully participate in other modalities, that is, work and action. Jansson (2019: 132-4) seems to associate the Finnish basic income experiment's aims to alter the so-called bureaucratic and welfare 'traps' related to low-paid and sporadic jobs primarily with the labour modality.

Second, the 'work' modality refers to diminishing poverty and enhancing self-determined lives and work performed to create useful, permanent and sustainable production, beyond just survival. This could mean that with basic income, people may have better options to refuse jobs that are unethical or deleterious to both humans and the environment. This type of thinking emphasises the meaning of paid work and work communities as a means to guarantee individuals' autonomy and well-being. Finally, the 'action' modality refers to human activity performed in relation to other people in the public sphere, such as voluntary work. Within the action modality, basic income may enhance participation and shared political activity in forms other than paid work. Hence, basic income may enable actions that aim to deepen democracy and shared political and/or participatory activity among citizens (Jansson, 2019).

\section{DATA}

To obtain the type of qualitative data needed, the Social Insurance Institution of Finland delivered our research group's interview invitation and informed consent form to half (988 people) of the basic income experiment participants by mail. Those willing to participate in a face-to-face interview were asked to mail their consent forms directly to our research group, which was the only party with access to the interview data at any stage. This procedure was the result of the study being an independent part of the experiment's evaluation by a research group at the University of Helsinki. Therefore, the transfer of personal data was contingent on the explicit consent of the basic income experiment participants only. Taking into account this procedure, in which reminders were not allowed, our initial goal was to receive at least 50 signed consent forms. However, the expectations were exceeded, and a total of 106 informed consent forms were obtained during the period 3 February-16 March 2019.

We chose to conduct semi-structured interviews, which enabled us to freely discuss several themes relating to participants' experiences. The interviews 


\section{Table 12.1 Interviewees' background information (number of persons)}

\begin{tabular}{lll}
\hline Gender & Female & 42 \\
& Male & 38 \\
& Non-binary & 1 \\
\hline Age & $25-34$ years old & 18 \\
& $35-44$ years old & 21 \\
& $45-61$ years old & 40 \\
& No information & 2 \\
\hline Residency & Uusimaa (including greater Helsinki area) & 27 \\
& Southern Finland & 21 \\
& Western Finland & 24 \\
& Northern and Eastern Finland & 9 \\
\hline
\end{tabular}

dealt with three core themes: (1) participants' general life situation and well-being; (2) unemployment, work, and bureaucratic encounters; and (3) interviewees' experiences as basic income experiment participants.

In our data collection, we kept conducting interviews until we reached a point at which we were assured that the accounts of basic income and the experiment started to resemble each other (e.g. Hennink et al., 2016). We ended up interviewing 81 people, notably more than our initial goal.

The interviews were conducted in quiet and easily accessible locations ${ }^{1}$ that were suitable for the interviewees and caused them no extra expenses to travel to. Three people employed for the project conducted the interviews. The first pilot interview was conducted on 14 January 2019 and the remaining 80 interviews between 7 February 2019 and 4 June 2019; 74 interviews were conducted in Finnish, four in Swedish, and three in English.

The interviews lasted between 27 minutes and 2 hours 22 minutes. In total, we ended up with 88 hours and 1 minute of recorded interview material. The interviews were transcribed verbatim, resulting in 3893 pages of transcribed data. All data extracts used in this chapter were anonymised and translated into English. ${ }^{2}$ We present information on the interviewees' backgrounds in Table 12.1 .

Approximately two-thirds of our interviewees reported that they had gained paid employment during the experiment; 25 interviewees had been working in either longer fixed-term or permanent positions; and 14 had undertaken short-time and/or on-demand work. Five interviewees worked in creative fields and six were entrepreneurs. Five interviewees performed work supported by a pay subsidy. Around one-third of the interviewees did not gain any form of paid employment during the experiment. Of these interviewees, nine had studied full time, one had acted as (an unofficial) caregiver, six had 
been receiving activation services that promoted employment, and 12 were not involved in any of these activities.

\section{ANALYSIS}

For our analysis, we first read our data to make sense of it as a whole. Then, for closer analysis, we collected all data passages that dealt with interviewees' accounts of the experiments' effects. For the next stage of the analysis, we applied theory-driven content analysis on relevant data passages that were organised in correspondence with prior theoretical knowledge (Elo and Kyngäs, 2008).

We analysed our data with respect to the labour, work, and action modalities identified by Arendt (1998 [1958]), as well as the assumed effects of basic income on these activities (see Jansson, 2019). Nearly all of the interviewees touched upon these three modalities in one way or another while making sense of their experiences, for example, by making multiple justifications when describing factors that contribute to unemployed people's access to paid employment. By analysing these three modalities, we aimed to exemplify the diversity of interviewees' social contexts and manifold accounts of the experiment's effects. However, by focusing on the analysis of these modalities, we excluded several intriguing interview themes that were beyond the scope of our analysis.

\section{The Labour Modality}

We identified two different ways in which the interviewees described the effects of the basic income experiment related to labour modality activities: everyday survival and consumption. The first way concerns interviewees' descriptions that portray the basic income experiment as having been meaningful for meeting their basic human needs and allowing them to secure necessary consumption through paid employment. The second way is associated with accounts in which the interviewees described the minimal or non-existent effects the experiment had on their employment, living conditions, and/or consumption.

In interview accounts in which basic income was said to have strengthened the labour modality, the enhanced possibilities for accepting, in particular, short-time, part-time and gig jobs were highlighted. Some interviewees stated that favourable tax conditions that were a part of the experiment design had resulted in them taking jobs that had otherwise been too poorly paid and insecure. Others, in turn, had regarded their basic income as allowing them to decline job offers perceived as being too insecure or having very poor working conditions. For some interviewees, basic income had provided economic secu- 
rity, enhancing their life situation between different jobs, gigs, or contracts. In particular, this security was associated with part-time and zero-hour contracts in which earnings were varied and job contracts were characterised by breaks in between.

During the basic income experiment, I was in a work trial that resulted in temporary contracts, and then an on-demand work contract. (--) When the experiment started, it immediately affected my mindset, that if I could get even small bits of work, I could have a chance to support myself. (--) Well, my salary was not amazingly high, so it [basic income] was a good supplement and I was able to get on very well with it during the experiment. And when I finished the temporary contract and got another, it was still really a good help for me. In particular, last summer, when I left that temporary contract and started this on-demand contract, it was an extra good supplement, as my earnings were really uncertain at the time. So it [basic income] brought loads of security to my life. (Interviewee 71)

The interviewees, however, talked about the labour modality in various ways, representing different ways of reasoning. For example, for some interviewees, the basic income experiment offered an opportunity to seek new options in the labour market, whereas others said that they had postponed their plans to study, for example, since it was worthwhile to work full-time and to have the untaxed basic income on top of their earnings. Hence, many interviewees stated that having a salary and basic income strengthened their ability to undertake long-term economic planning, for example, to consume, save money, and afford both basic necessities and small luxuries (see Hamilton and Mulvale, 2019: 588-90). However, some interviewees experienced economic difficulties and extra bureaucratic stress between jobs during the experiment, since unemployment insurance funds and trade unions had little knowledge of how the basic income affected earnings-related daily unemployment allowances.

Still, basic income combined with a salary was described as offering some of the interviewees a better living standard, instead of only covering everyday survival (cf. Jansson, 2019). During the experiment, some interviewees were able, for instance, to buy proper winter clothes or household appliances, to repair their car, to go to the cinema, to visit a restaurant, or to go to the hairdressers. Some interviewees had been able to invest in culture, travel, home decorating, visiting relatives, or children's recreational activities. Therefore, combining the basic income with a salary offered many interviewees a sense of security and continuity in their lives.

I feel that I am economically a little bit stronger now. On my own, I happened to find a therapist whom I meet once a month. Just speaking about my issues has helped me to move forward with my life. [...] Basically, this basic income has paid for my therapy, which has helped me to cope in working life. (Interviewee 4) 
Basic income was described as being particularly motivating in situations in which it was combined with a salary paid from subsidised work. However, not all interviewees had internalised the benefits of the untaxed basic income until subsidised work started, that is, keeping the basic income untaxed on top of any earnings. On the one hand, basic income was portrayed as strengthening incentives for working in the intermediate labour market. On the other hand, the experiment caused disappointment to some interviewees, since despite their hopes and wishes, they did not gain access to 'proper jobs' within the open labour market owing to work ability limitations.

When I got [from subsidised work with basic income] nearly the same sum as those who work as regular labourers, it motivated me insanely to work. To be honest, I was really upset when it [basic income] ended. I am a client of integrated services [Multi-sectoral Joint Service Promoting Employment], and the staff there told me many, many times that now it would be a profitable time to seek a job as one can get some extra money. [...] I have to say that it has bothered me that I didn't realise I could go somewhere earlier. Or, I don't know. [...] I had no work capacity then [...] I had long, long episodes in rehabilitative work and at the time, I had no strength to do proper jobs. I sort of have to admit it [not having working ability] to myself. Well, even these days, I sometimes have problems with my ability to cope, and my feelings are not always very good. (Interviewee 32)

Some interviewees described situations in which they had found it difficult to find employment, because they lacked work ability, or had only partial work capacity due to mental health issues, homelessness, or an otherwise difficult life situation. However, in these situations, some people gained paid employment at the end of the second year of the experiment. In these interview accounts, success in gaining employment is portrayed as a long-term project in which not just basic income but also support from officials and non-governmental organisations (NGOs) is described as meaningful. However, during the experiment, some participants were able to make longer-term plans for the future and to 'sort things out' after prolonged periods of unemployment.

I must have been quite difficult to employ before I got into this basic income experiment. I had problems with my driving licence and it looked like a knot that would not open in any way. [...] When this basic income thingy started, I got some type of drive. I immediately thought that, God dammit, I have 2 years to get my shit together, to do as I want to. And so it went. I am very satisfied with all the things I achieved during these 2 years. And as a cherry on the top, during the last month, I found a place to work, which seems relatively long lasting. [...] I mean, this experiment gave me 2 years' timeframe to see the horizon. That really, now I have time to breathe. (Interviewee 74)

The other way to describe the effects of experiments on the labour modality deals with descriptions of minimal or non-existent effects. In these cases, the 
interviewees had, for example, agreed to take on jobs prior to knowing about the experiment and/or jobs were easy to accept despite the experiment. Hence, the experiment was associated with little meaning vis-à-vis labour modality.

In other of these accounts, the interviewees made sense of the labour modality by presenting structural explanations for their situations. In these descriptions, the interviewees shared their aspirations with respect to the labour modality; however, heterogeneous reasons, such as their place of residence, age, disability, long-term illnesses, their educational background, and/or migrant status influenced their opportunities to gain employment (see also Calnitsky and Latner, 2017: 375, 390). Some interviewees also included descriptions in which the experiment was portrayed as 'unsuccessful' or 'wasted' in their cases, since their health or work ability did not allow them to strengthen the labour modality as a basic activity in their lives. Thus, in these cases, the experiment time was not described as differing significantly from the time of receiving traditional welfare.

Well, all kinds of [services for promoting employment] have been tried. But I just can't [participate in them for health reasons]. [...] If I think about [basic income] financially, I was 100 percent sure when it came, as it came so steadily. But now [with traditional unemployment benefit] it comes in 4-week cycles, and it comes when it comes. [...] So it was a little easier [with basic income]. [...] Otherwise, I can't say, whether my [life situation] would have been any different. In the same way, the sun rises in the morning and sets in the evening. (Interviewee 2)

However, interviewees who had long-term illnesses and work ability limitations expressed that the basic income offered some kind of security owing to its regularity. The unconditionality of basic income was portrayed as meaningful for covering basic necessities, such as rent and medicine. However, the amount of the basic income in the experiment was described as too low to cover all necessities for everyday survival.

\section{The Work Modality}

The interview accounts for the effects of the experiment related to work modality activities deal with their descriptions of improved possibilities for making meaningful and sustainable decisions in the labour market. In particular, the experiment revealed that the work modality was strengthened in the case of interviewees who had either studied or worked as specialists, small business owners, or in creative fields.

Those interviewees who worked in creative fields stated that the basic income experiment had particularly positive effects in their situations in which freelance fees, hourly paid work and/or grants were combined. These interviewees stated that the basic income helped them to accept project-based 
and sporadic work, as it came with diminished bureaucratic load and lack of coercion and sanctions associated with traditional welfare. In addition, the basic income experiment was portrayed as having been helpful in terms of professional confidence and courage to pursue artistic aspirations, as well as strengthening general well-being, sense of control, and agency (see also Calnitsky and Latner, 2017: 392).

Well, for sure, I can say that my well-being was better when I had basic income. It is about a feeling of freedom, and these psychological effects have been great. Whereas economically, the benefits have been nearly non-existent. But it is rather about not having that coercion in the background, so it increases creativity when you get the freedom. Then, creativity increases well-being. [...] So, it has provided me a feeling that I can focus on the matters that are relevant. [...] When the constant insecurity and regular hassle with benefits are gone, I mean the weariness of them, you can see that you are able to achieve miracles. When you don't always have to think whether I can accept this gig or not [without losing my benefits]. (Interviewee 6)

Interviewees who had worked in creative fields during the experiment said that the basic income was a relief for them owing to its economic predictability and stability. These aspects were portrayed as strengthening the interviewees' sense of security and helping them to free themselves from the stress related to income insecurity. However, these interview accounts on increased creativity were related to interviewees who had worked in creative fields prior to the experiment.

Not much has changed, as I have reported my doings [to the Public Employment Services] in a similar way to before the experiment. I have had similar job gigs. The only positive thing I can say as an artist is that when you know that 560 euros will be deposited monthly into your account, I don't have to think about how much my monthly income will reduce my unemployment benefit. So, it has brought me some economic security. [...] And when you work in creative fields, it has a massive mental meaning. I mean what goes on in your head and what kinds of stress levels you have, so it has a significant meaning. [...] 560 euros is no astronomic sum at all. [...] Practically, it didn't increase my annual income at all, but it brought me some regularity. (Interviewee 13)

Some of the interviewees also stated that the experiment had freed them to educate themselves. In these accounts, descriptions of autonomy were emphasised, since during the experiment one could study without the Public Employment Services regulating the content, duration or means of those 
studies. Thus, the basic income experiment freed some interviewees to channel their interests and motivated them to study instead of job seek.

Well, if I am being totally honest, I have to say that it [basic income] has decreased [my job seeking] a bit. [...] But I have tried to perceive it in a way that I will now invest in my studies. First of all, I am a job seeker, so if I will get a job offer, I will prioritise it, and my studies will be secondary then. But I haven't been able to choose between these two. So, in that sense, my answer to your questions is that it [basic income] has made me a little bit passive. [...] However, it has rather enabled me to be myself. Because, if I use the word 'unemployed', the status of an unemployed person, I have never liked it at all. Because it has so much to do with the idea that society patronises me. [...] And work life for me [as a specialist] has been very independent and I have always been trusted. And all of a sudden, I am unemployed and all the trust is gone. So, in that sense, the basic income offered me the option to be trusted again. During these 2 years, I have been able to actualise myself, to participate in different events and study. (Interviewee 8)

The basic income experiment also helped some interviewees to upskill themselves in fields that would have been difficult or impossible to access with traditional conditional unemployment benefits. In these interview accounts, the possibility of advancing participants' studies was described as more meaningful than trying to achieve economic gains with basic income.

I was studying in a field in which finding a job can be a little difficult. So [the basic income] was really a delightful thing for me [...] From time to time I thought, as I have that [anonymised] qualification, I could have gone to some [place of business] in Lapland for the summer, or some other place where there is a shortage of labour. But then again, it felt more meaningful to study. [...] I thought it was for my future. It was tempting to work, to get a basic income and salary, but then again, it felt more valuable and more important for me to find my own thing. (Interviewee 43)

Based on some of the interview accounts, the time during the basic income experiment was used to provide an option to find a balance in their general life situation, to practice 'self-seeking', to find one's 'own thing' or to reach for one's long-term hopes and dreams of finding meaningful work and activities.

When I had basic income, I felt it was really good, as I didn't feel that my mental health was okay at that time. I had hoped that I could have received rehabilitation benefits for a little bit longer so I could have been a bit more relaxed at that point and taken care of myself better. But I had a slow pace with my mental health recovery and it would have required a little bit more time. But then I had this basic income option. [...] When I was pursuing my dreams [of studies], it helped me to work myself. My mental health is loads better now, I feel that I am really stable now. (Interviewee 40) 
In interview accounts related to aims to achieve one's long-term aspirations, some interviewees described how the basic income experiment had encouraged them to start their own small businesses, since they provided the option to experiment with self-employment without any major financial risk. However, some interviewees stated that basic income had no effect on these plans, since they were made prior to the experiment. Nevertheless, the ability to do meaningful things for a living is at the core of these experiences.

In January, I realised that, hang on a second, I'm on basic income and I could afford to do this trick now. [...] It was a lot easier and nicer to start a business, when I knew I had at least some income in the background. [...] I thought that now I will try to do this, what I had been interested in doing. I thought that I have 2 years of time, and if everything gets fucked, at least I have tried it and I will not starve to death in between. Now, I have reached a point in which my business goes so well that there is no point of running it down, and get back on unemployment benefits. But then again, I have not got rich yet [so I have to do part-time work] [...] The biggest change is that now I can do things that I have always wanted to. I had an opportunity to make my hobby as something that I could do for 12 hours per day in a way that someone is paying something for it. So, at the moment, it means a lot to me, that it is my life. [...] But if the business needs to be shut down, I don't know. [My part-time job], for example, does not give me any of these feelings. It doesn't give any other feelings than that I wish this would be over for the day. (Interviewee 12)

The interviewees described how complex bureaucracy has prevented them from trying out self-employment prior to the experiment. However, these accounts also included statements that a two-year period was too short to establish a profitable business. In these interview accounts, the experiences were portrayed rather ambivalently, since they included descriptions of both self-actualisation and financial difficulties.

I started my own business in autumn 2017, by invoicing the client through my own business. I don't know whether it would have been possible without this basic income, because I can't even imagine the hassle I would have had with the Social Insurance Institution of Finland. I would have needed to negotiate with them and send them all kinds of receipts for invoicing. That would have been intolerable. So basic income enabled that for me. I could start up my own business; however, in the end, it wasn't cost-effective. [...] I had to close it down and think of other ways to invoice the clients then. [...] So honestly, I can't brag that it was a great thing to start up a business, since it wasn't profitable. (Interviewee 9)

In addition, within the work modality, the basic income experiment also offered some of the interviewees meaningful employment options in their fields of specialisation, for example, by gaining more relevant work experience or having an option not to react the job offers of the Public Employment Services. 


\section{The Action Modality}

The interview accounts also included content that can be related to action modality activities, that is, descriptions of the basic income experiment's effects on interviewees' societal and political participation as well as actions and interactions benefiting other human beings. These accounts included illustrations of how the basic income experiment had provided some interviewees with opportunities to participate in different political activities, voluntary work, and other non-paid activities, such as care work.

Overall, in their interview accounts, the interviewees conceptualised various activities performed outside paid employment as work. For example, some interviewees described how receiving basic income had given them freedom to participate actively in different NGOs or cooperative activities, without being accountable to the Public Employment Services.

[During the basic income experiment] I focused on activities of that co-operative. I was a chairperson of its board and a responsible account holder. [...] I could have applied for unemployment benefits, but I didn't, as I thought that basic income was enough. [...] I don't perceive myself as an unemployed person as I work so much. Even though I don't get any money out of it yet. [...] I believe I got a bit more self-confidence and ambition out of the fact that I didn't need to worry about the money or to all the time have to demonstrate to the Social Insurance Institution of Finland or the Public Employment Services that I need money and I do things in an active manner. I believe that basic income had a positive effect on my confidence and strength. (Interviewee 50)

Some interviewees stated that receiving basic income encouraged them to perform voluntary work, since there was no risk of losing benefits. However, typically, these interviewees had done voluntary work prior to the experiment too.

If I still would have that basic income, I could do some voluntary work. I have been working in a helpline service and as a support person. [...] I could do something actually meaningful, and reasonable things too. But, now I am sort of hanging here and waiting, waiting, and waiting. (Interviewee 3)

Some interviewees described how basic income had inspired them to undertake social and political activities, for example, to advocate for basic income or to deepen their knowledge of social policy in general. Some interviewees stated that as a result of the experiment, they had followed the news and daily politics in more detail, readjusted their political views, or participated in different events dealing with basic income. In addition, some interviewees shared their aspirations for participating in basic income studies as a means of being 'useful' for future research. Thus, some interviewees expressed their desire to 
help with and be part of knowledge production vis-à-vis basic income (see also Calnitsky, 2016: 30).

For sure, I wanted to participate [in this study], and with great inspiration, I am involved. This is a hot and topical issue around the world. I am very satisfied that I got selected, and I really hoped to participate in this face-to-face interview. Surely, this is a slow and tough way to influence, but this is how it works. (Interviewee 70)

Some interviewees also described how they had the flexibility to help and assist people during the experiment by adjusting their time use. This help included, for example, shopping for groceries for relatives, taking their neighbours' dogs out for walks, or babysitting their grandchildren.

I do gigs [at work] because my parent has early dementia and my husband is on a sickness benefit. [...] So also for my husband's sake I haven't been taking on permanent work, in case there will be situations that I couldn't have time off to help him. But now, when I do gigs, I can plan my schedule a little bit. [...] The guaranteed minimum income [basic income] provided me some alone time so I could regain some strength, too. [...] Also, during those 2 years, I was able to give a bit more time to my children and grandchildren, so I could make my working hours a little flexible. [...] So it [basic income] gave me own kinds of security and enough strength to cope with my family life. (Interviewee 47)

In the interview accounts, caring for relatives was portrayed as being easier in situations in which basic income was combined with self-employment and paid labour. These accounts overlapped all three modalities, since having the chance to focus on meaningful activities also freed energy to support close ones.

I take care of my brother's everyday life so that he survives. [...] Even though I am not an official guardian, I take care of all kinds of stuff he needs. [...] I have to say that during last year, I felt I was alive again. As I was able to actualise myself [in my own business] and do and try new things. [...] I remembered who I am again. Because of my family issues, I had years, a couple of years when I didn't think about myself at all. I just worked for other people, took care of them and helped them, so I sort of forgot who I am. I was sort of living some other person's life in a way. So during last year, I was able to focus on my own thing, even though I helped others, but I was prioritising myself. (Interviewee 16)

In particular, some interviewees stated that basic income had enabled them to help their ageing relatives who needed daily assistance, for example in cases of acute illnesses. In the interviewee accounts, the care work of elderly 
relatives was placed on a parallel with paid full-time work, compensated by basic income.

In my family, both my parents got ill at the same time. They are rather aged, so I have been acting as a voluntary care worker for a couple of years now. It has been a life situation that has occupied me a lot and it took time, since I have a different place of residence than my parents. So, I have moved to their place and been there physically. So, I haven't thought about work issues; rather, I have been making sure that my parents' everyday life flows, all their medical issues are in order, they have been to the doctors. [...] So I kind of think that this voluntary care work, I perceive it as work, it has been work what I have done with my basic income salary. [...] I said to my mother that you don't have to give me any money. That I perceive that this basic income money is my salary that I will take care of you two. That you don't have to be in any elderly care institution or be assisted by strangers. (Interviewee 28)

In addition, interviewees who were out of the paid labour market during the experiment described the economic security of basic income as meaningful for their social relationships and ability to help others.

I have been told that I was remarkably happier [during the experiment than now], maybe it was the peace I had with the money being always in my account. It brought so much security to my life. Now, when I don't have it, I am told that I am a similar bugbear as before. So in the autumn, I realised that God damn it, the time will come to its end. So, I had a little panic about what to do. [...] So now when this citizen's wage [basic income] ended, I didn't even have a chance to visit the swimming hall with my friend, as I needed to save money for the bus ticket. [...] I was too comfortable with my good situation. So, when it ended, it was quite a drop to anxiety. (Interviewee 10)

Thus, within the action modality, some interviewees stated that the basic income had an effect on their mental and general well-being, which influenced their ability to interact with other people on an everyday basis.

\section{CONCLUSIONS}

In this chapter, we analysed interview accounts by 81 participants in Finland's basic income experiment for the effects of the experiment vis-à-vis three modalities: labour, work and action (cf. Arendt, 1998 [1958]; Jansson, 2019).

The interview accounts of activities relating to the labour modality were varied. Some of the interviewees described the experiment as having had a substantial effect on their labour market behaviour, employment, and daily consumption. For example, the financial incentives of the experiment encouraged some of the interviewees to seek employment or hold on to their jobs, which were often low-paid and had relatively insecure working conditions. Some of the interviewees pointed out that the incentive to hold on to such jobs 
was connected to the additional income provided by the basic income, compensating for a low salary. According to the interview accounts, for some the basic income had instead given rise to the opportunity to change jobs, reduce hours worked, or decline jobs offers perceived as meaningless in essence or as exploiting workers' rights. Such power to say 'no' to undesirable jobs has been one of the central arguments for many proponents of a basic income (cf. Jansson, 2019; Van Parijs, 2013; Widerquist, 2013).

Some of the interviewees instead recounted that the experiment had little if any effects on their activities relating to the labour modality. In particular, interviewees who perceived themselves as having limited work capacity described the experiment as having had only minor effects on their lives. When having difficulties accessing paid employment, the basic income covered only the minimum necessities and daily consumption, if even those. Many of these interviewees also described difficulties in taking part in work and action modality-type activities, a situation which had, however, prevailed even before the basic income experiment. However, in such situations, basic income was still often described as enhancing the experience of financial security and continuity, as well as decreasing negative bureaucratic load and stress related to 'coercive' activation.

The interview accounts for the effects of the experiment also related to the work modality, which can be associated with self-determined life and sustainable as well as ethical production as a means to guarantee individuals' autonomy and well-being (cf. Arendt, 1998 [1958]; Jansson, 2019). In particular, the interviewees who had worked in creative fields described the basic income experiment as having strengthened their autonomy and ability to undertake meaningful work. In addition, the interview accounts related to self-employment and studying were associated with meaningfulness and ability to fulfil one's own long-term aspirations.

The interview accounts also included activities that can be associated with the action modality. Some interviewees described how receiving a basic income had provided them with the opportunity to undertake voluntary work and activities, such as care work, which had strengthened their experience of well-being. Thus, part of the benefits of the experiment had to do with the participants considering modes of social participation, such as performing non-paid voluntary or care work, to be more legitimate when obtaining basic income than when receiving unemployment benefits. In addition, some interviewees perceived such modes of participation as giving them the option of identifying themselves as working rather than belonging to the category of the unemployed (cf. the discussion on a basic income obscures the limits of 'work'). Thus, our results seem to lend some support to claims (e.g. Pateman, 2004) that basic income (experiments) may obscure perceptions of the divi- 
sion between 'work' and 'non-work', in our case, clearly affecting people's self-identity in positive ways.

The effects of the basic income experiment vis-à-vis the three modalities of labour, work and action were to some extent overlapping. Hence, the effects are varied and only partially fit the modality framework. Based on our analysis, people act by considering factors relating to all modalities in their activities. This means, for example, that an ability or will to accept a job is often tangled with more general reflections on work, family, economy, health and well-being. Often, these reflections seem connected to the variation regarding the premises of the interviewees, which are substantial even within the quite limited group studied (recipients of basic unemployment benefits from the Social Insurance Institution of Finland). Overall, the interview accounts on the effects of the experiment were often positive, but not all of them were. In particular, some interviewees who remained outside of paid employment described themselves as having 'failed' in the experiment, since they were not able to access the labour market. Thus, the interviews also reflect the explicit employment-related aims of the experiment.

However, the diversity in the accounts indicates that a basic income may respond to diverse social needs and various life situations in multiple ways (cf. Calnitsky and Latner, 2017: 390). Thus, our results can be interlinked with varied theoretical assumptions of basic income effects (for assumptions, see, for example, Jansson, 2019; Standing, 2002; Torry, 2019; Van Parijs, 2013; Widerqvist, 2013), although these often depart from the assumption that basic income is introduced to all members of society.

While our results point to some similarities with previous empirical qualitative interview study findings regarding positive aspects of basic income (Hamilton and Mulvale, 2019), making comparisons with such research and experiments is challenging, since they differ in design, objectives, and general socio-political contexts. The Finnish basic income experiment was strongly tied to employment policy goals, lasted for only two years, and had a relatively low monthly payment, albeit tax exempt. The target group comprised only recipients of basic, flat-rate unemployment benefits, and the experiment group was fairly small (2000 people). Such factors, as well as the broader framework of the welfare system as a whole, have to be considered when assessing our empirical results and conclusions.

In the 'Nordic welfare state'-type context, in which all residents are, as a rule, covered (at least) by some comparatively low, but statutory means-tested last-resort economic benefits, receiving (tax-exempted) unconditional basic income instead of flat-rate basic unemployment benefits, as in the case of the experiment participants, seems to have had varied consequences.

Most participants emphasised increased economic predictability and greater degrees of freedom of action as positive aspects of the income. However, 
for people engaged in (some) gainful employment, the basic income also presented the opportunity to increase living standards, and thus, to move from a life of plain 'survival' somewhat closer to 'normal' consumption levels.

For experiment participants who were not, for any multitude of possible reasons, active in the labour market, the experiment seems to have had limited effects on (material) living conditions and (the quite modest) consumption levels: often, the basic income amount paid during the experiment, even with other possible supplementary benefits (social assistance, housing allowances, etc.) received, was described as too low to cover all the necessities for everyday survival.

\section{NOTES}

1. The locations of the interviews were as follows: 34 interviews at public libraries, 16 in meeting rooms, four at coffee houses/petrol stations, 25 at interviewees' homes, and two at interviewees' work offices.

2. Some semantic differences exist between the original and translated data extracts.

\section{REFERENCES}

Arendt, H. (1998 [1958]), The Human Condition, 2nd edn, Chicago, IL: University of Chicago Press.

Birnbaum, S. and De Wispelaere, J. (2020), 'Exit strategy or exit trap? Basic income and the "power to say no" in the age of precarious employment', Socio-Economic Review, available at https://doi:10.1093/ser/mwaa002 (accessed 12 December 2020).

Bohmeyer, M. and Cornelsen, C. (2019), Was würdest Du tun? Wie uns das Bedingungslose Grundeinkommen verändert - Antworten aus der Praxis, [What Would You Do? How the Unconditional Basic Income is Changing Us - Answers from Practice], Berlin: Econ Verlag.

Calnitsky, D. (2016), 'More normal than welfare: The Mincome experiment, stigma, and community experience', Canadian Review of Sociology (Revue Canadienne de Sociologie), 53(1), 26-71.

Calnitsky, D. and Latner, J. P. (2017), 'Basic income in a small town: Understanding the elusive effects on work', Social Problems, 64(3), 1-25.

Davala, S., Jhabvala, R., Standing, G., and Mehta, S. K. (2015), Basic Income. A Transformative Policy for India, London: Bloomsbury.

De Wispelaere, J., Halmetoja, A. and Pulkka, V. (2018), 'The rise (and fall) of the basic income experiment in Finland', CESifo Forum, 19(3), 15-19.

De Wispelaere, J. and Stirton, L. (2004), The many faces of universal basic income, The Political Quarterly, 75(3), 266-74.

Elo, S. and Kyngäs, H. (2008), 'The qualitative content analysis process', Journal of Advanced Nursing, 62(1), 107-15.

Forget, E. L. (2011), 'The town with no poverty: The health effects of a Canadian guaranteed annual income field experiment', Canadian Public Policy, 37(3), 283-305.

Hamilton, L. and Mulvale, J. P. (2019), "'Human again”: The (unrealized) promise of basic income in Ontario', Journal of Poverty, 23(7), 576-99. 
Hennink, M. M., Kaiser, B. N., and Marconi, V. C. (2016), 'Code saturation versus meaning saturation: How many interviews are enough?', Qualitative Health Research, 27(4), 591-608.

Jansson, I. (2017), 'Lönearbete och medborgarlön - reflektioner utifrån Hannah Arendts vita activa' ['Paid work and basic income - Reflections based on Hannah Arendt's vita activa'], Socialmedicinsk tidskrift, 94(5), 603-9.

Jansson, I. (2019), Occupation and basic income through the lens of Arendt's vita activa, Journal of Occupational Science, 27(1), 125-37.

Kangas, O. and Pulkka, V. (eds) (2016), Ideasta kokeiluun? Esiselvitys perustulokokeilun toteuttamisvaihtoehdoista [From Idea to Experiment-Preliminary Report on a Universal Basic Income], Helsinki: Valtioneuvoston selvitys- ja tutkimustoiminnan julkaisusarja 13/2016.

McKay, A. (2007), 'Why a citizens' basic income? A question of gender equality or gender bias', Work, Employment and Society, 21(2), 337-48.

Pateman, C. (2004), 'Democratizing citizenship: Some advantages of a basic income', Politics \& Society, 32(1), 89-105.

Perkiö, J. (2020a), 'From rights to activation: The evolution of the idea of basic income in the Finnish political debate, 1980-2016', Journal of Social Policy, 49(1), 103-24.

Perkiö, J. (2020b), 'Legitimising a radical policy idea: Framing basic income as a boost to labour market activity', Policy \& Politics, 48(2), 277-93.

Sage, D. (2019), 'Unemployment, wellbeing and the power of the work ethic: Implications for social policy', Critical Social Policy, 39(2), 205-28.

Sauer, L. (2015), 'Das bedingungslose Grundeinkommen im Lichte der politischen Philosophie Hannah Arendts - Eine etwas andere Kritik der politischen Ökonomie', ['Unconditional basic income in the light of the political philosophy of Hannah Arendt - A somewhat different critique of the political economy'] in Osterkamp, R. (ed.), Auf dem Prüfstand: Ein bedingungsloses Grundeinkommen für Deutschland? [On the Test Bench: An Unconditional Basic Income for Germany?] Nomos: Sonderbände Zeitschrift für Politik 7, pp. 143-56.

Standing, G. (2002), Beyond the New Paternalism: Basic Security as Equality, London: Verso.

Standing, G. (2017), Basic Income and How We Can Make It Happen, London: Pelican Books.

Suuronen, V. (2018), 'Resisting biopolitics: Hannah Arendt as a thinker of automation, social rights, and basic income', Alternatives: Global, Local, Political, 43(1), 35-53.

Torry, M. (2019), The Palgrave International Handbook of Basic Income, London: Palgrave Macmillan.

Van Parijs, P. (1995), Real Freedom for All: What (if Anything) Can Justify Capitalism? Oxford: Oxford University Press.

Van Parijs, P. (2001), 'A basic income for all', in Rogers, J. and Cohen, J. (eds), What's Wrong with a Free Lunch?, Boston: Beacon Press, pp. 3-26.

Van Parijs, P. (2013), 'The universal basic income: Why utopian thinking matters, and how sociologists can contribute to it', Politics \& Society, 41(2), 171-82.

Widerqvist, K. (2013), 'The basic income grant as social safety net for Namibia: Experience and lessons from around the world', in Social Safety Nets in Namibia: Assessing Current Programmes and Future Options, The Annual Symposium 2013 of the Bank of Namibia, pp. 43-67, available at https://www.bon.com .na/CMSTemplates/Bon/Files/bon.com.na/0f/0fa7f5ba-5585-4471-9511 -1a42811bd0d1.pdf (accessed 18 December 2020). 